\title{
Reactive and Harmonic Current Detection in a Nonlinear Load with Frequency Excursions
}

\author{
M. E. Abdel- Karim \\ Electrical Power and Machines Dept., Faculty of Eng. \\ Tanta University, EGYPT
}

\begin{abstract}
In this paper, an effective estimator for detecting the reference current of active power filters and Var compensators is presented. The proposed estimator is adaptive and can be used with nonlinear loads under frequency excursions of the power source over a wide range. The effectiveness and accuracy of the proposed method are demonstrated and verified through the presented simulation and experimental results.
\end{abstract}

Keywords: Active filters, adaptive filters, harmonic elimination, reactive power compensation.

\section{Introduction}

The increased use of power converters, adjustable speed drives, electronic devices, and non-linear loads, contribute to excessive harmonic distortion in power systems. As a consequence, compensation of reactive and harmonic currents becomes more and more important.

So far, passive filters have been used for this purpose, however they have limitations to be overcome. Active filters and static Var compensators have been developed in recent years, but they require measuring systems with high accuracy and rapid detection for reactive and harmonic currents. Active power filters have been developed, such as the shunt active filter shown in Fig. 1 [1].

Several methods have been proposed for detecting harmonic and/or reactive currents. Conventionally, analog notch or band pass filters are used to extract harmonics in power system control. Recently, a control method based on realtime digital simulation of an LC filter for each harmonic accomplished by a DSP have been proposed. To adjust the harmonic current compensation in distribution lines via an active filter, adaptive gain controller has been used [2]. A drawback of these filters is that the corner frequency is sensitive to parameter variations of the elements and the filtering process will be worse as the ac source frequency fluctuates. To avoid this problem, an adaptive bandpass filter has been proposed to detect the harmonics current with wide range variations of ac source frequency $[3,4]$. 


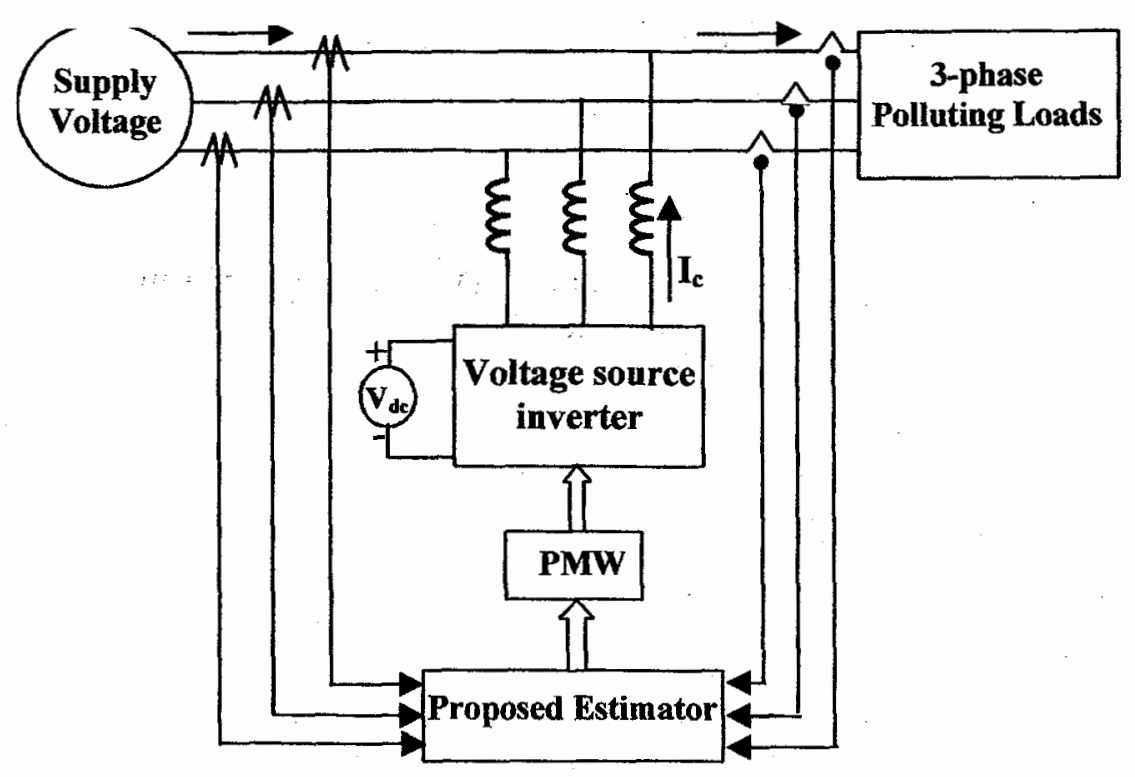

Fig.1. Voltage source inverter as a shunt filter.

Reactive and harmonic current reference can be determined in many different ways. Usually, integrative methods such as fast integration method [5], least compensation current method [6], Fryze's time domain analysis [7], and Fourier analysis $[1,7,8]$ are applied. These result in good steady state and moderate response of consequent line current to the load current change. Fast Fourier Transform (FFT) method needs two FFT transformations that take about $31 \mathrm{~ms}$ to complete $[7,8]$. In addition, a distorted voltage will cause a nonsynchronous sampling error. However, a detecting method based on instantaneous reactive power theory [9] and instantaneous active and reactive power $p-q$ method [10] are only suitable for a three-phase system. In implementation, these methods need several high accuracy multipliers. So its features are complicated in structure, difficult to adjust, and poor in performance. A multistage adaptive filtering system has been proposed to extract the sinusoidal active current from the distorted waveform without harmful phase shift even when the frequency and amplitude alter simultaneously [11]. However, due to the complexity of the model, the study. has been restricted to simulation. A compensator using control logic circuits operated in cycle-cycle controlled reference current has been proposed to compensate the reactive and harmonic current [12]. The main disadvantage of this method is that the amplitude of the supply current reference remains constant between all zero-crossing instants of the source voltage.

In addition to the above mentioned shortcomings, the methods are affected by voltage distortion, since their detecting systems are open loop which are sensitive to component parameter variations and operating conditions. These directly affect the measuring accuracy. Two closed loop detection methods were proposed [7, 13]. In reference [7], analog detection method based on adaptive interference canceling theory depending on the least squares algorithms to minimize the error signal between the actual and detected compensating current has been proposed. In addition to the well-known 
problems of using analog components, the shortcoming of this method is that it needs mathematical tools to ensure the optimal minimum error. Reference [13] uses a digital low-pass filter with fixed parameters to detect a reactive and harmonic current reference for a limited range of source frequency variations on the expense of degradation of the filter performance.

This paper presents a new closed-loop and instantaneous adaptive estimator based on adaptive band-pass digital filter for detecting the reactive and harmonic current reference in a non-linear load under frequency excursions of the power source over a wide range. The corresponding detection system is developed. Simulation and experimental results are given, which verify that, the proposed estimator overcomes the shortcomings of the methods mentioned above.

\section{The Proposed Estimator}

\section{1. Basic principle}

For supply voltage $v_{\mathrm{s}}$ given by

$$
\mathrm{v}_{\mathrm{s}}=\sqrt{2} \mathrm{v}_{\mathrm{s}} \cos \omega \mathrm{t}
$$

The non-linear load current in a power system, in general, consists of the following terms

$$
i_{L}(t)=i_{L 0}(t)+i_{L p}(t)+i_{L q}(t)+i_{L h}(t)
$$

where:

$$
\begin{array}{ll}
\mathrm{i}_{\mathrm{LO}} & \text { dc component, } \\
\mathrm{i}_{\mathrm{Lp}} & \text { active current (in-phase line current), } \\
\mathrm{i}_{\mathrm{Lq}} & \text { reactive current, } \\
\mathrm{i}_{\mathrm{Lh}} & \text { harmonic current. }
\end{array}
$$

Equation (2) can be further expanded in the general form [13]

$$
\begin{aligned}
\mathrm{i}_{\mathrm{L}}(\mathrm{t})= & \mathrm{I}_{\mathrm{L} 0}+\mathrm{I}_{\mathrm{Lp}} \cos \omega \mathrm{t}+\mathrm{I}_{\mathrm{Lq}} \sin \omega \mathrm{t}+\sum_{\mathrm{j}=1}^{\infty} \mathrm{I}_{\mathrm{L} 2 \mathrm{j}} \cos (2 \mathrm{j} \omega \mathrm{t}+\Phi 2 \mathrm{j}) \\
& +\sum_{\mathrm{k}=1}^{\infty} \mathrm{I}_{\mathrm{L}(2 \mathrm{k}+1)} \cos \left((2 \mathrm{k}+1) \omega \mathrm{t}+\Phi_{2 \mathrm{k}+1}\right)
\end{aligned}
$$

The first and second summations represent the even and odd harmonics. The only component that the mains should supply, is the active current $i_{L p}$. It can be noted that, the active filter supplies the compensation current $\left(i_{c}\right)$ that contains the dc component, the reactive, and harmonic currents for the load. Then, the main needs only to supply the active current. This can be easily accomplished by subtracting the active current component $i_{L p}$ from the load current $i_{L}$

$$
\mathrm{i}_{\mathrm{c}}(\mathrm{t})=\mathrm{i}_{\mathrm{L}}(\mathrm{t})-\mathrm{i}_{\mathrm{Lp}}(\mathrm{t})=\mathrm{i}_{\mathrm{L}}(\mathrm{t})-\mathrm{I}_{\mathrm{Lp}} \cos \omega \mathrm{t}
$$

By multiplying both sides of eq (3) by $\cos \omega t$; 


$$
\begin{aligned}
\mathrm{i}_{\mathrm{L}}(\mathrm{t}) \cos (\omega \mathrm{t}) & =\mathrm{I}_{\mathrm{L} 0} \cos (\omega \mathrm{t})+0.5 \mathrm{I}_{\mathrm{Lp}}[1+\cos 2 \omega \mathrm{t}]+0.5 \mathrm{I}_{\mathrm{Lq}}[1+\sin 2 \omega \mathrm{t}] \\
& +\sum_{\mathrm{j}=1}^{\infty} \frac{\mathrm{I}_{\mathrm{L} 2 \mathrm{j}}}{2}\left[\cos \left((2 \mathrm{j}+1) \omega \mathrm{t}+\Phi_{2 j}\right)+\cos \left((2 \mathrm{j}-1) \omega \mathrm{t}+\Phi_{2 j}\right)\right] \\
& +\sum_{\mathrm{k}=1}^{\infty} \frac{\mathrm{I}_{\mathrm{L}(2 \mathrm{k}+1)}}{2}\left[\cos \left((2 \mathrm{k}+2) \omega \mathrm{t}+\Phi_{2 \mathrm{k}+1}+\cos \left(2 \mathrm{k} \omega \mathrm{t}+\Phi_{2 \mathrm{k}+1}\right)\right]\right.
\end{aligned}
$$

If $a$ band pass filter whose center frequency is at $2 \omega$ and its input is as given by eq (5), the filter output becomes

$$
\Delta \mathrm{i}_{\text {ep }}(\mathrm{t})=0.5 \mathrm{I}_{\mathrm{Lp}} \cos 2 \omega \mathrm{t}+0.5 \mathrm{I}_{\mathrm{Lq}} \sin 2 \omega \mathrm{t}
$$

This output is treated to obtain $i_{c}$ in a compensating current estimator circuit by adding a feedback loop and an integral gain block as shown in Fig. 2.

\section{2. General Description of the estimator}

To analyze the estimator circuit shown in Fig. 2, assumes it has reached a steady state condition, since the integrator forces its average input $\Delta \mathrm{I}_{\mathrm{ep}}$ to zero. With this condition, the integrator output $I_{\mathrm{ep}}$ becomes a dc. If this dc value is multiplied by $\sin \omega t$ or $\cos \omega t$, the closed loop modifies the integrator output to the peak value of the reactive or active current component respectively. In the case of multiplying this dc value by $\cos \omega t$ as shown in Fig. 2, the multiplier output becomes;

$$
i_{\text {ep }}(t)=I_{\text {ep }} \cos \omega t
$$

At the summing node, after the subtraction takes place, the feedback signal to the active current estimator block becomes;

$$
\mathrm{i}_{\mathrm{c}}(\mathrm{t})=\mathrm{i}_{\mathrm{L}}(\mathrm{t})-\mathrm{i}_{\text {ep }}(\mathrm{t})=\mathrm{i}_{\mathrm{L}}(\mathrm{t})-\mathrm{I}_{\mathrm{ep}} \cos \omega \mathrm{t}
$$

After multiplication with in-phase sinusoid, eq (7) becomes;

$$
\begin{aligned}
\mathrm{i}_{\mathrm{c}}(\mathrm{t}) \cos \omega \mathrm{t} & =\mathrm{i}_{\mathrm{L}}(\mathrm{t}) \cos \omega \mathrm{t}-\mathrm{I}_{\mathrm{ep}} \cos \omega \mathrm{t} \cos \omega \mathrm{t} \\
& =\mathrm{i}_{\mathrm{L}}(\mathrm{t}) \cos \omega \mathrm{t}-0.5 \mathrm{I}_{\mathrm{ep}}(1+\cos 2 \omega \mathrm{t})
\end{aligned}
$$

The multiplication output enters the band-pass filter and the output due to the first term of eq (8) is eq (6). The band-pass will eliminate the dc component ($\left.0.5 I_{\mathrm{ep}}\right)$ in the second term of eq (8), and will pass $-0.5 \mathrm{I}_{\mathrm{ep}} \cos 2 \omega \mathrm{t}$. Then, the total filter output is:

$$
\Delta \mathrm{i}_{\text {ep }}=0.5 \mathrm{I}_{\mathrm{Lp}} \cos 2 \omega \mathrm{t}-0.5 \mathrm{I} \text { ep } \cos 2 \omega \mathrm{t}+0.5 \mathrm{I}_{\mathrm{Lq}} \sin 2 \omega \mathrm{t}
$$

The average of the reactive current, the third term in eq (9), during one quadrant cycle becomes zero. In addition, the integrator forces the second term to equal the first term, i.e. $I_{e p}$ equal to $I_{L p}$. In this form, the estimated active current $i_{\text {ep }}(t)$ is an accurate representation of the in-phase actual active current $i_{L p}(t)$ in the power circuit. In this case, the estimator output $i_{c}(t)$, eq $(7)$, represents the actual compensating current that contains the dc component, the reactive and harmonic currents for the load. 


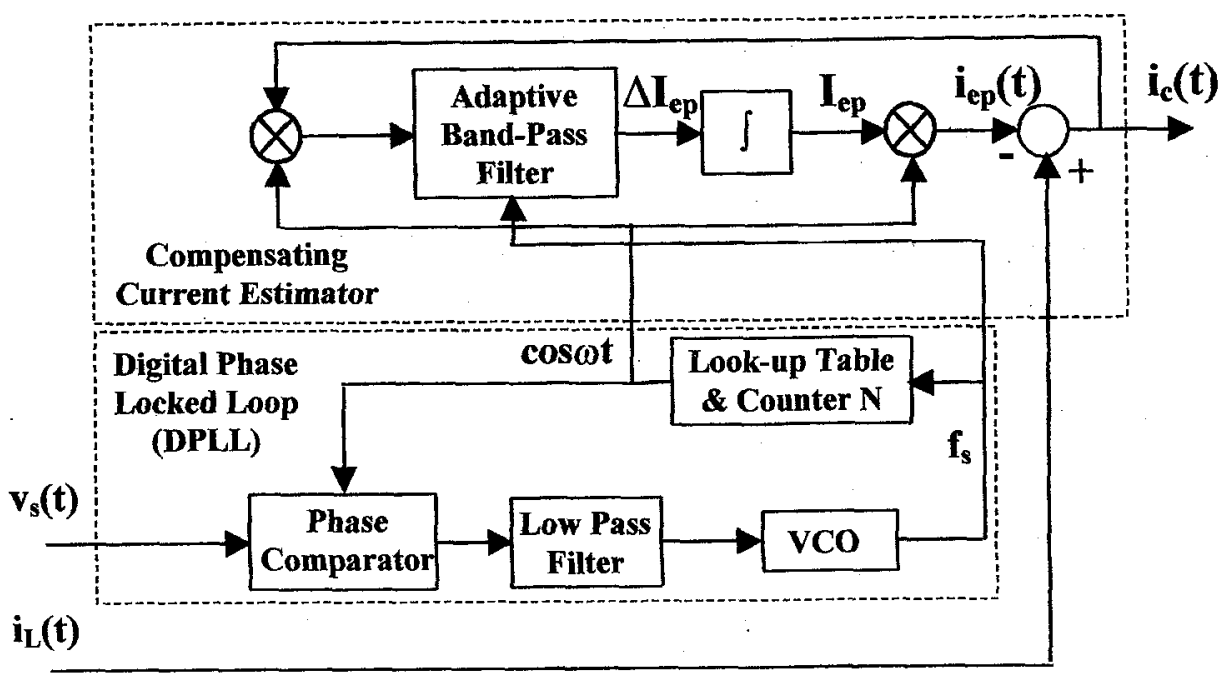

Fig.2. Closed-loop diagram for estimating the compensating current.

The proposed estimator requires a low-distortion sinusoid with good phase tracking with respect to the supply voltage. To get this clean in-phase sinusoid (cos $\omega t$ ), a digital phase-locked loop (DPLL) is used as shown in Fig. 2. However, its amplitude is not relevant.

\section{2. 1. Adaptive band-pass filter}

The adaptive band-pass filter is necessary to extract the second harmonic current signal filtering from $i_{c}(t) \cos \omega t$ as shown in Fig 2, especially for the frequency variations of supply voltage. This current signal is filtered by a digital infinite impulse response (IIR) band-pass filter whose transfer function in z-domain is:

$$
G(z)=\frac{\beta_{0}\left(1-2 z^{2}-z^{4}\right)}{1+\alpha_{1} z+\alpha_{2} z^{2}+\alpha_{3} z^{3}+\alpha_{4} z^{4}}
$$

where, the filter coefficients are listed in the appendix.

This digital filter is transformed from the normalized analog second order Butterworth low-pass filter $[14,15]$ :

$$
G(s)=\frac{1}{1+\sqrt{2} s+s^{2}} \quad \text { where } \quad s=\frac{1-2 \cos \left(\omega_{0} t_{s}\right) z+z^{2}}{z^{2}-1}
$$

The filter coefficients are determined for sampling frequency $f_{s}\left(1 / T_{s}\right)$ and a center frequency $f_{0}$, which must be equal to the frequency $2 f_{1}$ of the fundamental supply voltage, as stated above. However, the frequency variations of the supply voltage need the filter parameters to be adjusted to twice the frequency of the fundamental. This method involves so many computations. In addition, the value of this frequency must be known, which is not an easy task. So, in order to force the center frequency of the filter to follow the input frequency without changing its coefficients, the sampling frequency $f_{s}$ must be proportional to the fundamental frequency $f_{1}$ by a frequency multiplier $\mathrm{N}$, i.e. $\mathrm{f}_{\mathrm{s}}=\mathrm{Nf}_{1}[3]$. With this condition, and by putting 


$$
\begin{aligned}
& z=e^{j \omega T_{S}}=e^{j 2 \pi f_{1} / f_{S}}=e^{j 2 \pi / N}, \text { eq (10) becomes; } \\
& G(z)=\frac{\beta_{0}\left(1-2 e^{j 4 \pi / N}-e^{j 8 \pi / N}\right)}{1+\alpha_{1} e^{j 2 \pi / N}+\alpha_{2} e^{j 4 \pi / N}+\alpha_{3} e^{j 6 \pi / N}+\alpha_{4} e^{j 8 \pi / N}}
\end{aligned}
$$

It can be noticed from eq (11) that, the filter characteristics (magnitude and phase) do not change with the frequency variations. Keeping the ratio between $f_{s}$ and $f_{1}$ constant, a counter $N$ is added to the DPLL as shown in Fig. 2.

\section{2. 2. Digital phase-locked loop}

The concept of digital phase-locked loop (DPLL) is used to implement the supply voltage in-phase sinusoidal generator and the counter $\mathrm{N}$ as shown in Fig. 2 [16]. This permits one to obtain zero phase error under steady state over a wide range of input frequencies, restricted only by the band width of the lowpass filter and the control range of the sinusoidal voltage controlled oscillator. The exact phase tracking with respect to the input is ensured by the integrator of the low-pass filter $\left(1+\mathrm{T}_{1} \mathrm{~s}\right) / \mathrm{T}_{2} \mathrm{~s}$. The linear interpolation technique is used to generate an accurate $\cos \omega t$, with a minimum harmonic distortion, from a lookup table with the adaptive sampling frequency $\mathrm{f}_{\mathrm{s}}\left(-\mathrm{Nf}_{1}\right)$. In this look-up table, sine values for $\mathrm{N}$ angles, which are uniformly spaced around the unit circle, are stored. The DPLL accepts a square wave as an input, the ideal transducer for this circuit is a fast electronic transducer ( $40 \mu \mathrm{s})$ of type (LV25 from LEM), which provides a galvanic isolation, and a good tracking with respect to the supply voltage.

\section{Simulation and Experimental Results}

\subsection{Parameters election}

The parameters for the integrator and the band-pass filter were adjusted empirically by means of computer simulation for a $50 \mathrm{~Hz}$ system. A suitable time constant for the integrator was found to be $0.0007 \mathrm{sec}$. The center frequency of the band-pass filter was adjusted to $\mathrm{f}_{0}=100 \mathrm{~Hz}$, as stated in section 2, with bandwidth $=12 \mathrm{~Hz}$, and sampling frequency $\mathrm{f}_{\mathrm{s}}$ is $5 \mathrm{KHz}$, i.e. $\mathrm{T}_{\mathrm{s}}=0.0002 \mathrm{sec}$. According to these values and from the appendix, the filter parameters are $\alpha_{1}=-3.754, \alpha_{2}=5.473, \alpha_{3}=-3.658, \alpha_{4}=0.949$, and $\beta=0.00033$. With these parameters and taking $z=e^{j \omega T_{s}}$ in eq $(10)$, the filter magnitude and phase characteristics at the center frequency, i.e. $\omega=2 \pi(100 \mathrm{~Hz})$, are 1 and $0^{\circ}$ respectively. The attenuation and phase at $\omega=2 \pi(50 \mathrm{~Hz})$, are $-32.76 \mathrm{~dB}$, and $12.38^{\circ}$. Also, the attenuation and phase at $\omega=2 \pi(150 \mathrm{~Hz})$ are $-32.88 \mathrm{~dB}$, and $12.29^{\circ}$. However, one comes to the conclusion that only the second harmonic present eq (8) to generate eq (9) respectively at the output of the band-pass filter and the other components are likely to be small or not present at all. According to eq (11) and for a constant value of frequency multiplier ( $N$ was taken 100), the above filter characteristics do not change with the supply frequency variations.

The DPLL was adjusted in order to operate properly in the range of frequencies from 15 to $100 \mathrm{~Hz}$. However, a larger frequency operating range is possible. 


\section{2. Evaluation}

For evaluating the efficiency of the proposed estimator, a very distorted waveform is constructed, as shown in Fig. 3a. The fundamental component of the test signal varies from $40 \mathrm{~Hz}$ at the sweeping rate of $80 \mathrm{~Hz} / \mathrm{sec}$. This fundamental component was resolved into its two active and reactives: components. The active component is taken as a fixed component, while the magnitude of the reactive component was suddenly changed by 1.5 times $s$ : Besides, the test signal contains an offset current; several low-order harmonics up to the $9^{\text {th }}$ component. Accordingly, for the supply voltage reference $v^{2}$ given by eq (1), and load current is:

$$
\begin{aligned}
\mathrm{i}_{\mathrm{L}}= & 0.25+3 \cos \mathrm{xt}+0.5 \mathrm{a} \sin \mathrm{xt}+\frac{\mathrm{a}}{3} \cos (3 \mathrm{xt}+0.3)+\frac{\mathrm{a}}{5} \cos 5 \mathrm{xt} \\
& +\frac{\mathrm{a}}{7} \cos 7 \mathrm{xt}+\frac{\mathrm{a}}{9} \cos 9 \mathrm{xt}
\end{aligned}
$$

where $\mathrm{x}=2 \pi 50+\mathrm{rt}$

a varies from 1.5 to 3 at 0.47 second;

$r$ rate of frequency variation, $80 \mathrm{H} / \mathrm{sec}$.

When the test signals, eqs $(1,12)$, are applied to the proposed estimator shown in Fig. 2, the simulation results of Fig. 3 (left) clearly show that the proposed estimator very well tracks the amplitude and ramp frequency variations of the load current shown in Fig $3 a$. The compensating current reference $i_{c}(t)$. is illustrated in Fig $3 \mathrm{~b}$. Figure $3 \mathrm{c}$, illustrates the estimated active current along with ideal active current (term 2 in eq 12). As mentioned above, this estimated active current remains unchanged and is nearly locked in phase and in magnitude with ideal active current and in-phase with the supply voltage reference (Fig. 3d). From Fig. 3c, it can be observed, that the reactive and harmonic components would be effectively attenuated if the compensating current $i_{\mathcal{c}}$ of Fig. $3 b$ was scaled and injected into the power system in Fig. 1. Figure $3 \mathrm{e}$ illustrates the band-pass filter output with a frequency of twice the fundamental. Figure $3 \mathrm{f}$ shows the integrator output with constant average value as expected from eq (12) and Fig. 3c. These figures ensure the behaviour of the proposed estimator that has been derived in section 2 .

\section{3. Implementation}

The software was implemented in LabView and $\mathrm{C}$. The routines that perform the compensating current estimator in real time are implemented in $\mathrm{C}$. The execution of these routines is fired periodically by the computer timer routines. The estimator routines sample the external signals and use the parameters defined in the parameters buffer to calculate the compensating current $\left(i_{c}\right)$. Some of the signals are stored in the signals buffer allowing the LabView virtual instruments (VI's) to monitor them. 

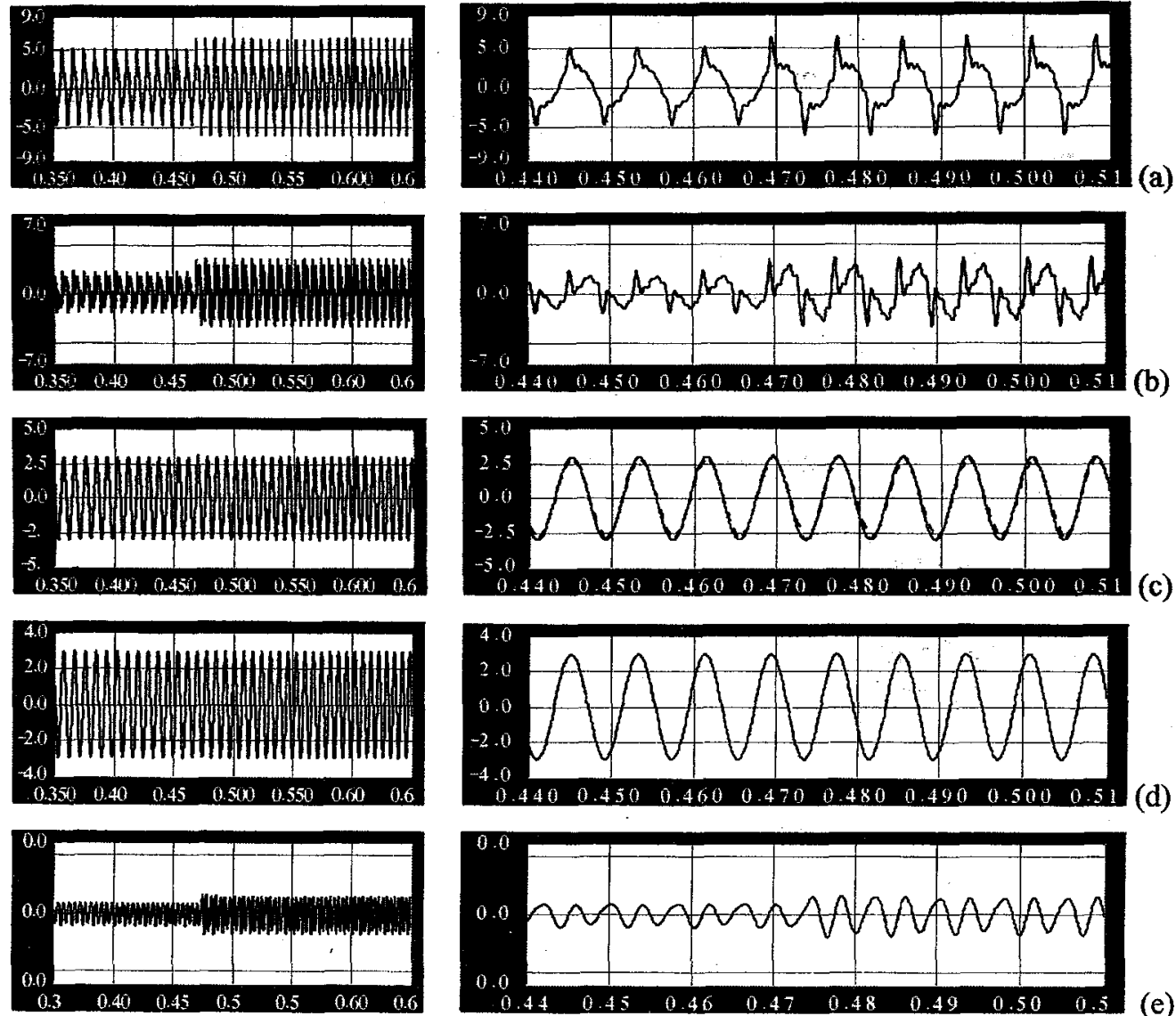

(e)
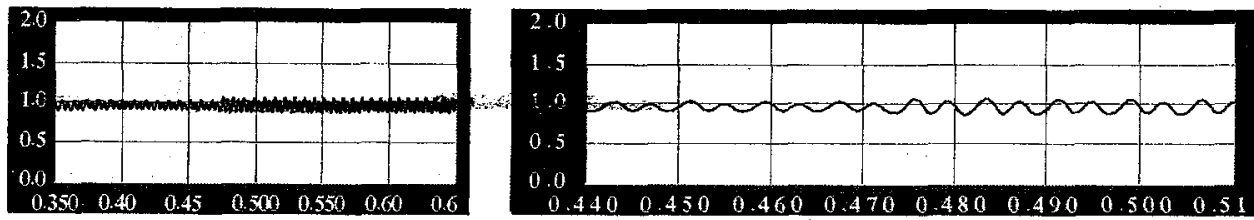

Fig.3. Simulation with distortion wave signals (eqs 1 and 12) with amplitude and frequency variations. (a) Load current, $i_{L}$. (b) Estimated compensating current, $\mathbf{i}_{\mathrm{c}}$. (c) Solid line: ideal active current, $\mathrm{i}_{\mathrm{Lp}}$; dashed line: estimated active current, $\mathrm{i}_{\mathrm{ep}}$. (d) Supply voltage reference, $\mathrm{v}_{\mathrm{s}}$. (e) Band-pass filter output, $\Delta \mathrm{i}_{\mathrm{ep}}$. (f) Integrator output, $I_{\mathrm{ep}}$. (At right, zoomed portion between 0.44 and $0.51 \mathrm{sec}$ )

The LabView VI's work as a graphic user interface that allows one to start the estimator, define the reference signals, change the parameters of the estimator, and monitor the signals through charts and graphs.

These VI's are linked to the external $\mathrm{C}$ routines, which run in the background in real time. The communication between the external $\mathrm{C}$ routines and the LabView VI's is accomplished through some VI's that read from the buffers using code interface nodes (CINS). While, the $\mathrm{C}$ routines acquire the data from the data acquisition card, Lab-pc1200 using NI-DAQ driver software.

\section{4. Application}

Figure 4 shows the proposed estimator implemented with a speed controlled wound-rotor induction motor driving a constant mechanical load torque. The motor generates reactive and harmonic currents due to the employment of a 
PWM transistor-controlled capacitive network in the rotor circuit with a faxed carrier frequency [17]. The reactive and harmonic stator currents san be adjuste 1 by varying the capacitor network. The constant mechanicateded is implemented by using a closed loop current control through a PI controfien ind a half-controlled thyristor bridge with constant current reference for a separately excited dc machine.

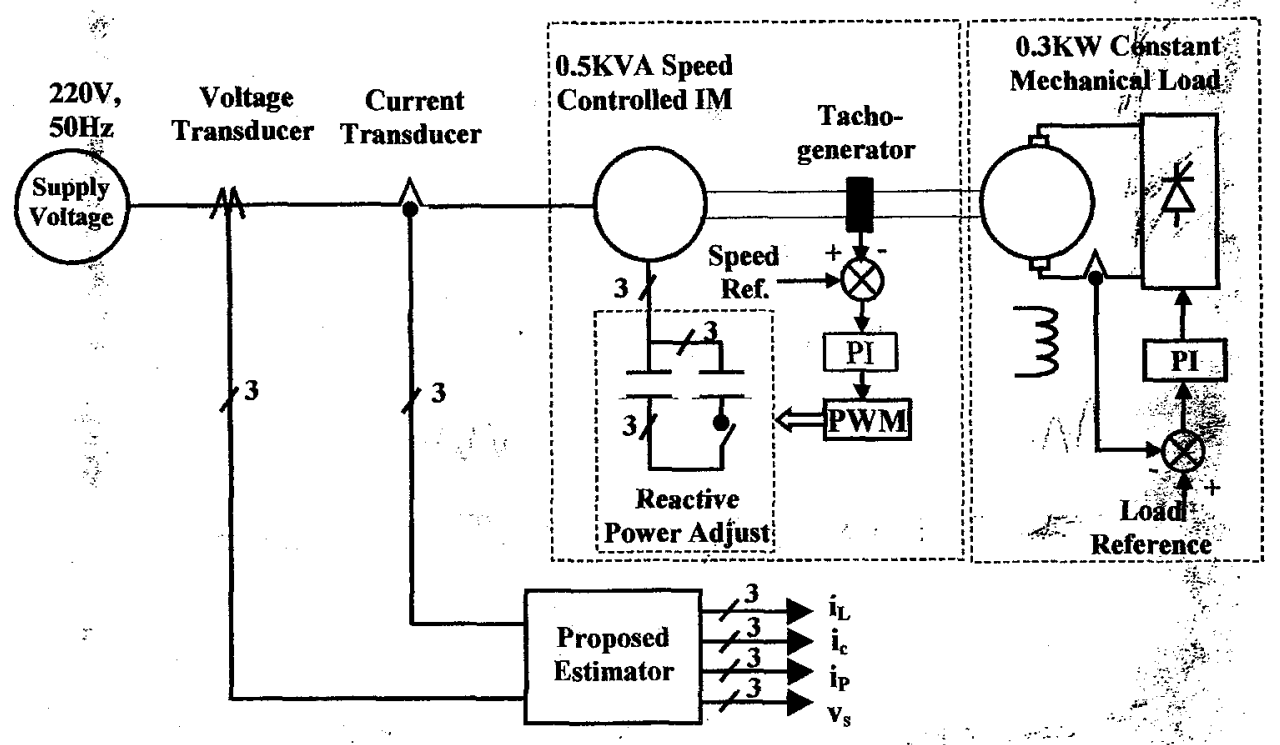

Fig.4. Experimental circuit with a speed controlled induction motor as a load.

In order to have a fixed stator active current, the mechanical load torque is fixed at a constant speed of induction motor. This can be achieved at constant current reference for the dc machine and at constant speed reference for the induction motor. Under these conditions, and at capacitor per phase of $11 \mu \mathrm{F}$, the stator currents have fixed values of harmonics, active, and reactive components as shown in Fig (5). Then, each rotor capacitor was suddenly increased to $20 \mu \mathrm{F}$ to have reactive and harmonic currents step change in the stator currents. After this, the estimated active current remains unchanged and no significant perturbation is introduced by reactive and harmonics current step change in stator currents as shown in Fig. 5c. In Fig. 5, trace (a) is the stator current, $i_{L}(t)$, trace (b) is the estimated compensating current which contains high frequency ripples, harmonics, sub-harmonics, and reactive currents produced in the stator current, $i_{c}(t)$. Trace $(c)$ is the estimated active current, $\mathrm{i}_{\mathrm{p}}(\mathrm{t})$, and trace (d) is the reference supply voltage, $\mathrm{v}_{\mathrm{s}}$, trace $(\mathrm{e})$ is the output of the band-pass filter, $\Delta \mathrm{i}_{\mathrm{p}}(\mathrm{t})$, with $\mathrm{a}_{\text {frequency of twice the fundamental }}$ frequency. Trace ( $f$ ) is the motor speed and the integrator output, $\mathrm{I}_{\mathrm{p}}$ with constant average value. These figures verify the behaviour of the proposed estimator as expected in section 2 .

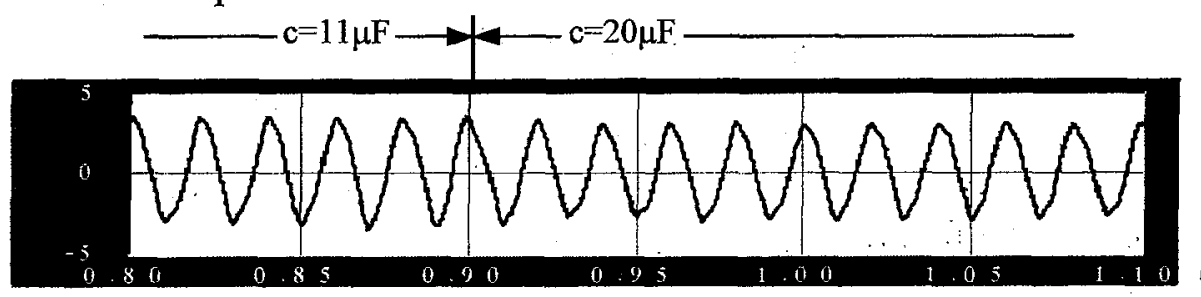




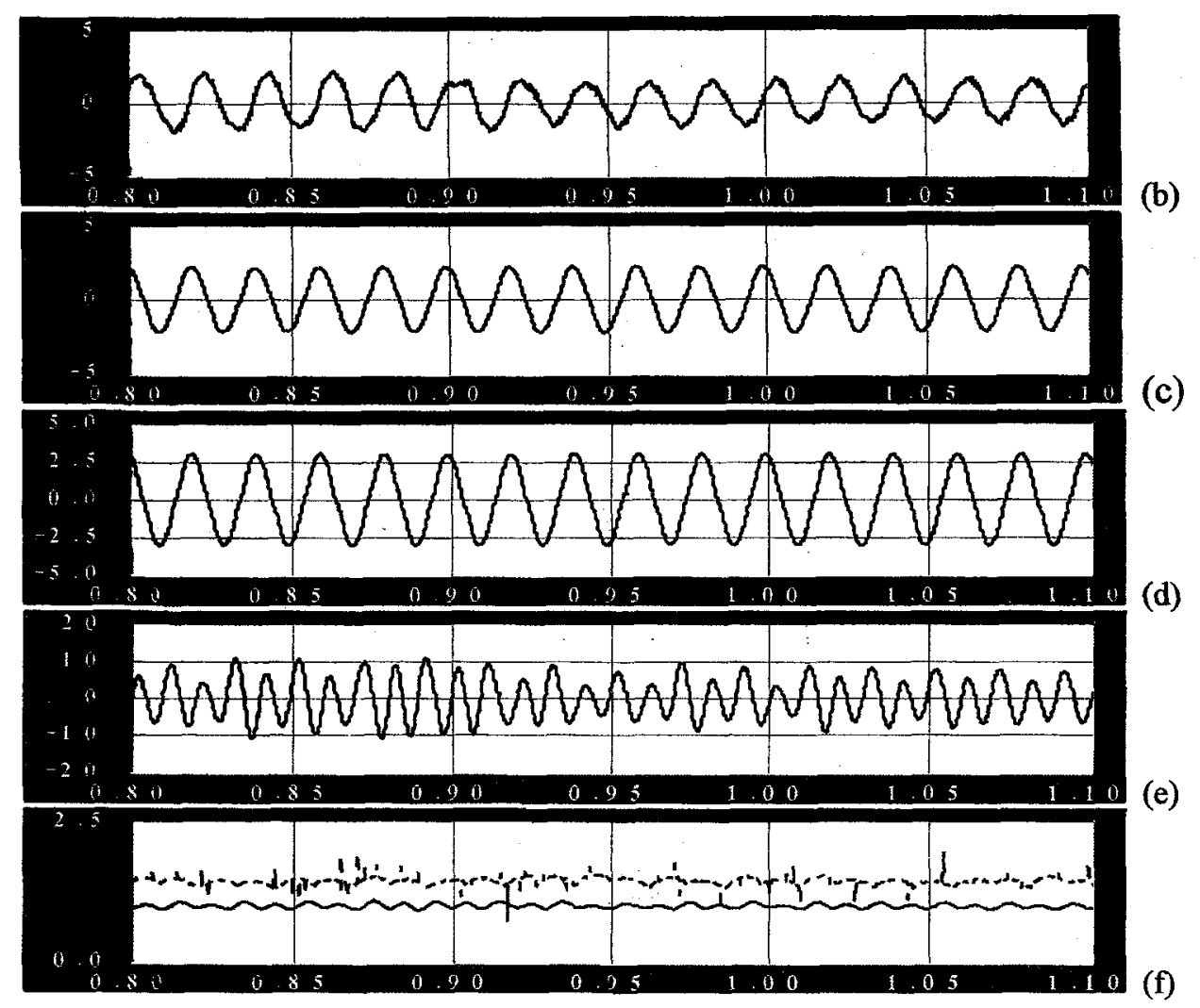

Fig.5. Experiment for capacitor step in the controlled induction motor $(50 \mathrm{~Hz})$. (a) Stator current, iL $0.5 \mathrm{~A} / \mathrm{div}$. (b) Estimated compensating current, $i_{c} 0.5 \mathrm{~A} / \mathrm{div}$. (c) Estimated active current, $i_{\text {ep }} 0.5 \mathrm{~A} / \mathrm{div}$. (d) Supply voltage reference, $\mathrm{V}_{\mathrm{s}} 100 \mathrm{v} / \mathrm{div}$. (e) Band-pass filter output, $\Delta \mathrm{i}_{\mathrm{ep}}$. (f) Dashed line: motor speed $1000 \mathrm{rpm} / \mathrm{div}$; solid line: Integrator output, $\mathrm{I}_{\mathrm{ep}}$.

\section{Conclusions:}

An adaptive estimator for detecting the instantaneous reactive and harmonic current reference has been proposed and presented. This is applicable for 1- $\Phi$ or 3-Ф active power filters and static Var compansators which allows harmonic elimination and power factor correction in nonlinear loads. Simulations and experimental results showed that, the proposed estimator requires no adjustment due to the continuously regulated closed loop action. Also, the results showed that, the estimator structure is capable of extracting compensation reference from strong disturbances efficiently, even if there are considerable frequency and amplitude variations. The estimator operates satisfactorily in the range of frequencies from about $15 \mathrm{~Hz}$ to a limit restricted only by the frequency response of low-pass filter of DPLL and the speed of computations. This estimator, along with its simplicity, is superior to traditional open-loop systems of evaluating the compensation reference in nonlinear loads. Besides this, the estimator can accurately detect and measure the active, reactive or any of its multiple harmonic current in the load. This can be achieved by adjusting the parameters of the band-pass filter, at the start only, according to the component to be measured and multiplying the integrator output by a supply voltage-phase sinusoid of that component. Finally, the ability to operate under varying frequencies makes this circuit useful for wariable frequency power systems. 


\section{References}

[1] H. Akagi, "New trends in active filters for power conditioning," IEEE Trans. on Ind. Applications, vol. 32, no. 6, November/December 1996.

[2] Y. Sato, T. Kawase, M. Akiyama, and T. Kataoka, "A control strategy for general-purpose active filters based on voltage detection," IEEE Trans. on Ind. Applications, vol. 36, no. 5, Sept./Oct. 2000.

[3] M. E. Abdel-Karim, "Digital signal processing for control of power converters", $\mathrm{PhD}$ Thesis, I.N.P.L, Nancy, France, and Faculty of Eng., Menoufia Univ, Shebin El-Kom, Egypt (Channel system), 1991.

[4] M. E. Abdel-Karim, and A. I. Taalab, "A refined detection of a reference signal for convereter controls under distortion and frequency excursion", EPE Journal, vol. 6, no. 34, Dec. 1996.

[5] D. Nedelijkovic, J. Nastran, D. Voncina, and V. Ambrozic, "Synchronization of active power filter current reference to the network", IEEE Trans. on Ind. Electronics, vol. 46, no. 2, April, 1999.

[6] L. Zhou and $\mathrm{Z}$. $\mathrm{Li}$, "A noval active power filter based on the least compensation current control method", IEEE Trans. on Power Electronics, vol. 15, no. 4, July 2000.

[7] S. Luo. and Z. Hou, "An adaptive detecting method for harmonic and reactive currents", IEEE Trans. on Ind. Electronics, vol. 42, no. 1, Feb. 1995.

[8] P. Papamichalis, and J. So, "Implementation of fast fourier transform algorithms with TMS32020," Digital Signal Processing Applications, Taxes instruments, 1988.

[9] H. Akagi, Y. Kanazawa, and A. Nabae, "Instantaneous reactive power compensators comprising switching devices without energy storage components," IEEE Trans. Ind. Applicat., vol. IA-20,, May/June 1984.

[10] V. Soares, P. Verdelho, and G. Marques, "An instantaneous active and reactive current component method for active filters", IEEE Trans. on Power Electronics, vol. 15, no. 4, July 2000.

[11] S. Valiviita, and S. J. Ovaska, "Delayless Method to generate current reference current reference for active filters", IEEE Trans. on Ind. Electronics vol. 45, no. 4, August 1998.

[12] K. Chatterjee, B. G. Fernandes, and G. K. Dubey, "An instantaneous reactive volt-ampere compensator and harmonic suppressor system", IEEE Trans. on Power Electronics vol. 14, no. 2, March 1999.

[13] J. S. Tepper, J. W. Dixon, G. Vếnegas, and L. Moran, "A simple frequency-independent method for calculating the reactive and harmonic current in a nonlinear load," IEEE Trans. on Ind. Electron., vol. 43, no, 6, Dec. 1996.

[14] L. Milic, U. Kamsck, and A. Jocic, "Analysis of filter bank transfer function", IEE proceeding, vol. 134, no. 1, Feb. 1987.

[15] N. K. Bose, "Digital filters", University Park, Pennsylvania, North Holand, 1984. (book)

[16, J. Hein, and J. Scott, "Z-domain model for discrete-time PLL's", IEEE trans. on Circuits and systems, vol. , no. 11, 1988.

[17] A. E. Lashine, S. M. R. Tahoun, and F. A. saafan, "A new approach to the speed control of wound rotor induction motors", Alexandria Engineering Journal, vol. 38, no. 3, May 1999.

\section{Appendix}

\section{Parameters of the Digital Band-Pass Filter}

$$
\begin{aligned}
& \beta_{0}=\omega_{\mathrm{a}}^{2} / 2 \quad \alpha_{1}=2 \sqrt{2}\left(\omega_{\mathrm{a}}-\sqrt{2}\right) \cos \omega_{0} \mathrm{~T}_{\mathrm{s}} / \mathrm{a} \\
& \alpha_{2}=2\left(1-\omega_{\mathrm{a}}^{2}+2 \cos ^{2} \omega_{\mathrm{a}} \mathrm{T}_{\mathrm{s}}\right) / \mathrm{a} \\
& \alpha_{3}=4\left(\omega_{\mathrm{a}} / \sqrt{2}-1\right) \cos \omega_{0} \mathrm{~T}_{\mathrm{s}} / \mathrm{a} \\
& \alpha_{4}=\left(\omega_{\mathrm{a}}^{2}+\sqrt{2} \omega_{\mathrm{a}}+1\right) / \mathrm{a}
\end{aligned}
$$

Where, $\quad \cos \omega_{0} \mathrm{~T}_{\mathrm{S}}=\frac{\cos \left(0.5\left(\omega_{\mathrm{L}}+\omega_{\mathrm{H}}\right) \mathrm{T}_{\mathrm{S}}\right)}{\cos \left(0.5\left(\omega_{\mathrm{L}}-\omega_{\mathrm{H}}\right) \mathrm{T}_{\mathrm{S}}\right)}, \quad \omega_{\mathrm{a}}=\frac{\cos \omega_{0} \mathrm{~T}_{\mathrm{S}}-\cos \omega_{\mathrm{L}} \mathrm{T}_{\mathrm{S}}}{\sin \omega_{\mathrm{L}} \mathrm{T}_{\mathrm{S}}}$,

$\omega_{0}, \omega_{\mathrm{L}}, \omega_{\mathrm{H}}, \mathrm{f}_{\mathrm{s}}\left(1 / \mathrm{T}_{\mathrm{s}}\right)$, are center angular frequency, lower and higher cutoff angular frequencies, and sampling frequency of band-pass filter. 
مبين للثيار غير الفعال وتو افقيات الأمال اللاخطية المفذاة من مصدر ذى ترددات متباينة

$$
\begin{aligned}
& \text { د مصطفى السيد عبد الكريم } \\
& \text { قسم هندسة القوى والآلات الكهريية } \\
& \text { كلية المثلدسة - جامعة طنطا }
\end{aligned}
$$

ملنخص البحث

تعتبر دوائر القدرة الإلكترونية من أهم مسببات التوافقيات ووجود القدرة غير الفعالــــة في أنظمسـة

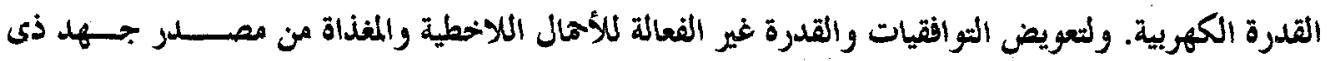

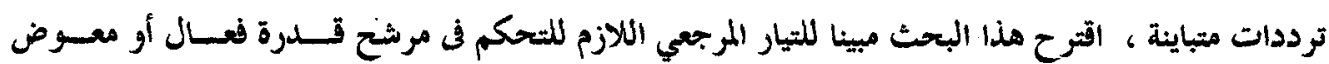

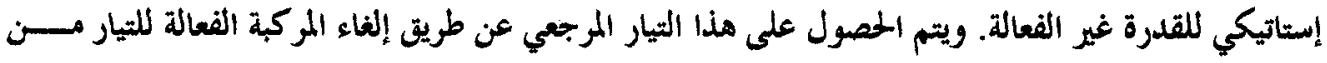

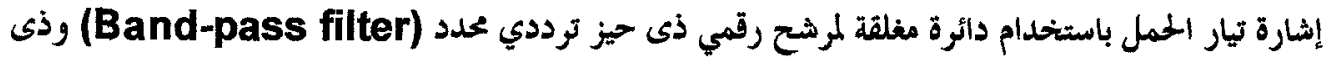

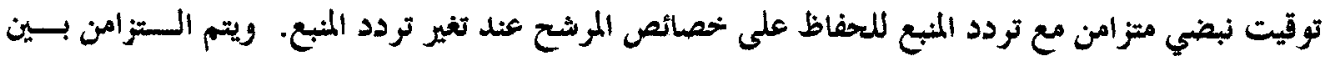

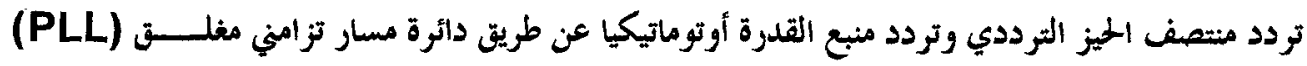
مرتبطة بتردد المنبع.

تم دراسة كيفية إتمام عملية الحصول على الثيار المرجعى من تيار حل لاخطي للطريقــــة المقترحسـة.

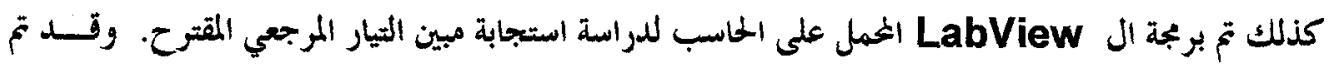

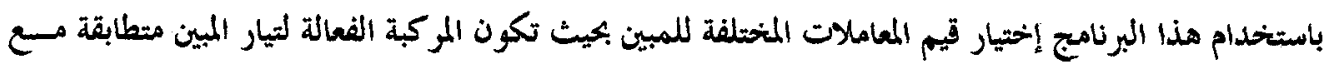

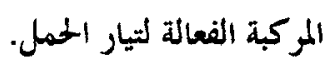

تم انتبار المبين المقترح معمليا مع محرك تأثيري ثلاثي الأوجه يتم التحكم فى سرعته عن طريق دائسرة

تحكم مغلقة بخموعة مكثفات متصلة بعضوه الدوار - وذلك عن طريق بطاقة إخراج وإدنحال بيانات (DAQ)

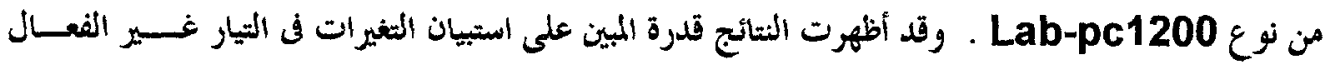

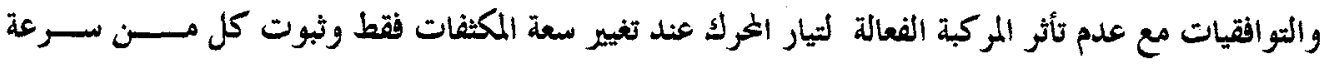

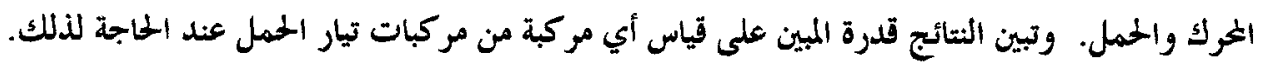

